Gießen

\title{
ZUR SEMANTIFIZIERUNG VON ZAHLWÖRTERN: DAS WORT 'TAUSEND' - EINE GERMANISCH-BALTOSLAVISCHE ISOGLOSSE?
}

\section{A. VORBEMERKUNG}

Gegenüber den Zahlen bis 'zehn' sind die unmittelbar darauffolgenden Zahlen in den indogermanischen Sprachen durchsichtige Bildungen. Das liegt daran, daß das indogermanische Zahlensystem auf dem Dezimalsystem aufgebaut ist und sich von der Zahl 'elf' an Beziehungen zu 'zehn' herstellen lassen. Was nun die höheren Zahlen, nämlich die für 'hundert' und 'tausend', angeht, so ist die Zahl 'hundert' auf 'zehn' ('zehn mal zehn') und die Zahl 'tausend' auf 'hundert' ('zehn mal hundert') beziehbar. Weil dem so ist, ist zu erwarten, daß Sprecher indogermanischer Sprachen für sie undurchsichtige Wörter für 'hundert' oder 'tausend' nach dem Wort 'zehn' bzw. 'hundert' umgebildet oder neugebildet haben. In der Tat ist dies bei dem gotischen Wort 'hundert' der Fall: Got. taíhuntehund (1mal), taíhuntaíhund (3mal), das synchron als 'zehn Einheiten zu Hundert', d.h. 'in bezug auf Hundert', gedeutet werden konnte (Lühr 1977: 65), hat die Kontinuante von urgerm. * $\chi u n đ a^{n}$ 'hundert' ersetzt. Auch bei dem Wort 'tausend' sind derartige Einflußnahmen zu vermuten. Während aber für das Wort 'hundert' mit Sicherheit ein einziges urindogermanisches Wort rekonstruiert werden kann, verhält es sich bei dem Wort 'tausend' anders. Ai. sahásram, av. haza eine Sprachgruppe, der mit got. pūsundi usw., aschwed. púsand, lit. túkstantis (älter túkštantis), lett. tũkstuotis, aksl. tysęšti, tysošti ${ }^{1}$ usw. eine andere gegenübersteht. Nach verbreiteter Ansicht ist das Wort 'tausend' dabei eine der auffallendsten lexikalischen Übereinstimmungen zwischen dem Germanischen, Baltischen und Slavischen. Auch Pijnenburg (1989: 100ff.) tritt in seinem Beitrag "Eine germanisch-baltoslawische Isoglosse" für die Gleichsetzung ein. Nach einer kritischen Überprüfung der in neueren etymologischen Wörterbüchern, Handbüchern, Grammatiken und Monographien erschienenen Deutungen kommt er zu dem Schluß, daß im Jahr 1986 nach wie vor Feists Feststellung aus dem Jahre 1939 (1939: 505f.) gilt: "Im einzelnen ist in der Bild. der Formen noch manches unklar". Demgegenüber zielt Pijnenburgs Beitrag auf eine Lösung der "Formprobleme" ab, wobei aber die "semantische Seite der Sache - die 'eigentliche' Bedeutung" "höchst problematisch" bleibe. Er rekonstruiert ein

$1 \quad$ Nach Rosenkranz (1955: 107) scheint tysošti makedonisch und tysęšti bulgarisch zu sein. 


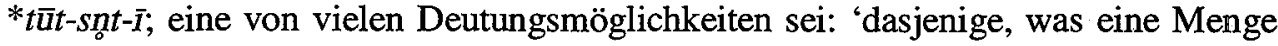
bildet; eine große Quantität bildend'. Mit dieser Deutung schließt sich Pijnenburg, was das zweite Element betrifft, der Auffassung van Heltens (1905: 121f.) an, der für das Wort 'tausend' ebenfalls von einer Zusammensetzung mit Hilfe des Partizips von *es- 'sein', nämlich *snt-ī (vgl. ai. satî́), ausging. Anders als Pijnenburg sah aber van Helten in dem ersten Bestandteil des Kompositums ein *tūs- in der Funktion eines Substantivs, das wie lat. flōs 'Blume' gebildet sei. Dieser Ansatz ist jedoch wie alle diejenigen Erklärungen, die von einem Bestandteil *tūs- ausgehen, ohne Zusatzannahmen lautlich unhaltbar.

Betrachtet man nun Pijnenburgs Deutung, so wären mit dem Ansatz *tūt-sñt-ī in der Tat eine Reihe von Problemen gelöst. Es sind jedoch nur die lautlichen Probleme diese sind bei Pijnenburg in aller Ausfiuhrlichkeit dargestellt und brauchen daher im folgenden (B I) nicht noch einmal vollständig abgehandelt zu werden; übrig bleiben Probleme, die die Morphologie und Wortbildung betreffen:

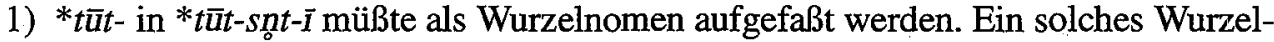
nomen existiert aber sonst nicht. Got. puthaurn 'Trompete' ist keine Parallele, da put- wie dt. tuten vermutlich onomatopoetischen Ursprungs ist (Feist 1939: 506).

2) Eine Zusammensetzung aus einem Wurzelnomen und einem Partizip des Verbs 'sein' entspricht keinem geläufigen germanisch-baltoslavischen Kompositionstyp ${ }^{2}$.

Da also Pijnenburgs Deutung des Wortes 'tausend' nicht überzeugt, soll im folgenden die Problematik des germanischen und baltoslavischen Wortes 'tausend' erneut aufgerollt werden. Es wird zu zeigen versucht, welche Schwierigkeiten sich ergeben, wenn man mit Pijnenburg an einer germanisch-baltoslavischen Isoglosse festhält ${ }^{3}$ und dabei Lautliches, Morphologie und Wortbildung angemessen berücksichtigt. Die Diskussion der übrigen Erklärungsversuche ergibt dabei, daß möglicherweise eine der bereits vorgenommenen Deutungen haltbar ist. Doch müssen etliche Modifikationen vorgenommen werden.

2 Meid 1967: 25ff.; Senn 1966: 340f.; Brugmann 1906: 67f. Im Altindischen fungieren Komposita mit einem Partizip Präsens im Hinterglied als verbale Rektionskomposita (z.B. ai. divi-spŕśant- 'den Himmel berührend'), oder das Vorderglied ist ein Präfix (z.B. ai. sú-vidvāmis- 'wohlkundig'); vgl. Wackernagel 1957: $193 f$.

3 So auch Schelesniker 1987:233. Jedoch würden die im Slavischen, Baltischen und Germanischen bei dem Wort 'tausend' vorliegenden "untereinander unklaren Lautverhältnisse" daher rühren, "daß dieses Wort so ziemlich unter die letzten Bildungen der losen Dialektgemeinschaft fällt." 


\section{B. HAUPTTEIL}

\section{Die bisherigen Erklärungsversuche}

Pijnenburg teilt die bisherigen Erklärungsversuche des Wortes 'tausend' nach drei Hauptlinien:

1) 'Das Wort ist eine Zusammensetzung von idg. * $t \bar{u} s$ - 'stark, kräftig, viel' und idg. *Kmt-ia $*$ * Kmt-iom, das wiederum von der Wurzel von idg. *Kmtóm 'hundert'4 abgeleitet ist"5.

2) "Das Wort ist eine Ableitung mittels eines (Partizip-)Suffixes *-ent-, *-ont-, *-ntvon einem Wort idg. * $t \bar{u} s{ }^{-"}{ }^{\prime 6}$. Hinzuzufügen ist Hamps (1973: 174) Ansatz $* t \bar{u}-s k$ ont-, ein Partizip Präsens von einem Präsens auf ${ }^{*}-s k$ -

3) "Das Wort ist eine Entlehnung, sei es des Germanischen aus dem Slawischen, sei es des Slawischen aus dem Germanischen".

Hinzu kommt die These 4), daß das Wort 'tausend' im Baltischen, Slavischen und Germanischen erst einzelsprachlich und damit unabhängig voneinander aus *tūsund dem Wort 'hundert' zusammengesetzt ist.

Im Falle von These 1) ist der in der Forschung schon angebrachten Kritik zunächst einmal hinzuzufügen, daß wegen des Ablauts im Altkirchenslavischen und im Altschwedischen eine Vorform *túHs-Komt-ih ${ }_{2},{ }^{*} t u ́ H s-K m t-i e h_{2}-s$ 'Krafthundert'? , die mit Ausgleich ein Nebeneinander von *túHs-Komt-ih ${ }_{2}$ und ${ }^{*} t u ́ H s-k m t-i h_{2}$ ergeben hätte, anzusetzen wäre. Doch bleiben auch bei einem solchen Ansatz die immer wieder zitierten Einwände, von denen die folgenden die wichtigsten sind, bestehen:

a) $\mathrm{Da}$ uridg. ${ }^{*} s K \mathrm{zu}$ balt. $-s t$ - wird (Leumann 1942: 126f.; Hamp 1973: 174ff. und Anm. 4), ist nach wie vor nicht erwiesen, wie das bekannte Gegenbeispiel alit. ieška (neulit. ieško) 'sucht', lett. iẽskâju 'lause', aksl. isko (neben išto mit -št-aus der 2. Sg. išteši $<* i$ išč- $)^{8}$ 'suche (auf), fordere' < urbaltoslav. *'énske/a- < vorurbal-

4 Die urindogermanische Vorform des Wortes 'hundert' wird auch als *Kñtóm angesetzt und $m$ in lit. šiñtas, lett. simts als Angleichung an das Wort 'zehn' (lit. dešimtìs, lett. desmit, dial. desimt) betrachtet (Kent 1929: 345; Peeters 1978: 28; Bengtson 1987: 257).

$5 \quad$ Zuerst Bugge 1888: 326f.; ferner Jensen 1952: 55; Porzig 1954: 142; Polomé 1972: 51. Pinault (1989: 63) verweist für die Bedeutung “'fort-cent" von "germ. thus-hundi" auf toch. A wälts, B yaltse <*w'ältsa< *ueld ${ }^{h}$ ' force' (nach Rix 1991: 226 Anm. 4 jedoch recte *unel-tio-m 'große Zahl' [Windekens 1976: 66; 1979: 198, 202] oder *ueldom).

6 Vgl. Schade 1872/1882: 937. Eine unwahrscheinliche Mischung der ersten und zweiten These nimmt Brugmann (1911: 48f.) vor: Neben dem Kompositum 'Krafthundert' habe es "eine gleichlautende, in beiden Gliedern deklinable Wortverbindung gegeben..., die bestand aus einem mit einem $n t$-Formans gebildeten Adjektiv mit der Bedeutung 'schwellend, kräftig, stark' (vgl. etwa got. nēhr undja 'der nächste'...) und dem Substantivum *kmató-m ('kräftiges, starkes Hundert')."

$7 \quad$ Vgl. Comries (1992: 792) Ansatz $*_{t} \bar{u}(s)-k_{m} t-$, wobei das erste Element mit ai. $t u v i$ - 'sehr' verwandt sei. Da nicht nur im Germanischen, sondern auch im Slavischen und Baltischen (vgl. unten) Suffixablaut auftritt, kann dieser Ablaut keine germanische Neuerung sein (anders Lloyd/Springer 1988: 354). 
toslav. ${ }^{*}$ eisske/o- zeigt ${ }^{9}$. Gegenüber dem ererbten $s k$-Präsens uridg. ${ }^{*} h_{2} i s-s k e / o$ - (ai. iccháti, av. isaiti 'sucht, wünscht') ist in vorurbaltoslav. *einske/o- wohl die Dehnstufe aus dem für das Vorurbaltoslavische zu postulierenden $s$-Aorist $*$ ēis $s$ < $* h_{2}$ ëiss-s- eingeführt (Klingenschmitt 1982: 67 Anm. 5 als eine Möglichkeit). Fälle wie lit. $p a$-žístu (Infinitiv pažinti), lett. pa-zĩstu 'kenne, erkenne' (vgl. lat. nōscō, ap. xšnāsa-, arm. čanač 'em < uridg. * ğnh $_{3}$-sKe/o- 'erkennen'), lit. gìmstu, lett. dzimstu 'werde geboren' (vgl. griech. Bóo $\sigma \kappa \omega$, ai. gácchati < * $g^{w}{ }_{0}$-skelo- 'kommen') sind sekundäre Bildungen, die sich dem Präsenstyp nasaler Wurzelauslaut + st-Suffix (rimstu, rimti 'ruhig werden') angeschlossen haben; mit lit. gimstu vgl. das danebenstehende aus dem Aorist hervorgegangene Präsens gemù 'werde geboren' (Infinitiv giñmti) (Stang 1966: 337ff.).

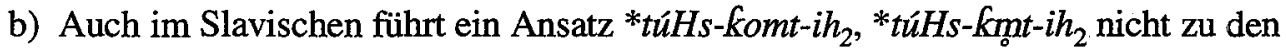
bezeugten Lautformen. Wie aksl. isko deutlich macht, hätte sich vor velarem Vokal *tyskoštti ${ }^{10}$ ergeben; und was die Form mit ę betrifft, so weist kslav. voštan๖ 'wächsern' < *voskěnъ, eine Ableitung von aksl. voskъ 'Wachs' (lit. vãškas), auf eine Lautentwicklung zu $s ̌ t$ vor (ursprünglich) palatalem Vokal hin. Aus ${ }^{*} t u ́ H s-k m t-i h_{2}$ wäre demnach ein aksl. *tyštę̌sti hervorgegangen.

c) Im Germanischen kann keine bereits vorurgermanische Zusammensetzung *túHs$\mathrm{km} t-i h_{2}$, deren Elemente nicht mehr segmentierbar waren, fortgesetzt sein; denn die Kontinuante von $*_{s-k}$ wäre wie inlautendes $*_{s k}$ behandelt worden, und $*_{s k}$ (*sK) bleibt unverschoben; vgl. an. loskr 'schlaff, träge' (air. lasc; Meid 1967: 195). Doch besteht die Möglichkeit, daß *-kmt- in vorurgerm. *túHs-Kmt-ih $h_{2}$ auf das Wort 'hundert', *kontóm, bezogen worden ist und *-k-dann Anlautsbehandlung $\left(>^{*} \chi\right)$ erfahren hat. Das Ergebnis wäre dann ein urgerm. * $p \bar{u} s-\chi u n d \bar{i}$. Da die Fortsetzung von * $\chi$ aber nur in aisl. púshund, aisl., runenschwed. (Stein von Saleby II) püshundrað auftaucht und das Wort sonst kein inlautendes $h$ aufweist (got. pūsundi; anord. púsund '1200', seltener '1000', awn. pl. púsundir, runenschwed. púsind, aschwed. púsand, púsund; ahd. dūsunt, thüsunt, tūsent; as. thūsundig; andl. thüsint; ae. püsend; afries. thüsend; Ross/Berns 1992: 621), müßte in diesem Fall $h$ wie in anord. likame, ae. licuma lautgesetzlich geschwunden, im Altnordischen jedoch teilweise restituiert sein ${ }^{11}$ - das von Grimm (1868: 253f.) als Stïtze angeführte salfränk. thüschunde, thuis chunde, tos chunde 'Großtausend, 1200'

9 Shevelov 1964: 141. Demgegenüber treten Endzelin (1923: 111), Bräuer (1961: 172) und andere für den Lautwandel von uridg. ${ }^{*} s k$ zu slav. $s$ und lit. $\breve{s}$, lett. $s$ und damit für einen Zusammenfall mit den Fortsetzungen von uridg. ${ }^{*} K$ ein. Doch sind auch in anderen Palatalsprachen die Vertretungen von uridg. ${ }^{*} s K$ und $* \widehat{K}$ verschieden (Arumaa 1976: 154). Lit. aũšti 'tagen, dämmern', dessen -š- Brugmann (1897: 568) wegen ai. ucchäti 'leuchtet' von einer Lautfolge *-s-sk- herleitet, kann $\breve{s}<*_{s}$ wie in lit. aušrà 'Morgenröte, Morgendämmerung' aufweisen. Ebensowenig ist aksl. pasQ 'weide' ein eindeutiges Beispiel für den Wandel von *sK zu aksl. $s$.

10 Im folgenden wird für den Nominativ Singular im Altkirchenslavischen die sich aus den Casus obliqui ergebende Form mit -š- aus $-\breve{s} t-<*-t i-$ angegeben.

11 Kluge 1901: 491; 1913: $\S$ 66: Als "Spiritus asper" verklingt $h$ frühzeitig in der Kompositionsfuge. 
bleibt fern, weil ch nur steht, wenn chunna vorausgeht (van Helten 1900: 515). Daneben besteht die Möglichkeit, daß die allein ein $-s$ - aufweisenden Formen, die die überwiegenden Lautungen sind, etwas Altes, $h$-haltiges aisl. pūshund und aisl., runenschwed. püshundrað aber eine "lectio facilior" darstellen, da sich deren $h$ leicht als volksetymologische Angleichung an das Wort 'hundert' erklärt (Hirt 1896: 345$)^{12}$. Ist dem so, so wären für das Urgermanische die Formen *būsundī, * $p \bar{u}$ sandī der korrekte Ansatz.

Die zweite, von Pijnenburg (1989: 103) als "Ableitungstheorie" bezeichnete These besteht aus drei Varianten: Es wird Ableitung angenommen erstens durch ein $n t$ Suffix in "verstärkender, elativierender Funktion", die im Slavischen und Baltischen in Wörtern wie russ. bol'šuščij 'sehr groß', lit. gražiñtelis 'wunderschön', seniñtelis 'steinalt', jauniñtelis 'blutjung' noch vorhanden sei (Aitzetmüller 1991: 140 und Anm. 205), zweitens durch ein Adjektivsuffix wie in got. neh'undja 'der Nächste' (Hirt 1896: 347) und drittens durch ein Partizipialsuffx *-nt-. Die letzte These stammt von Szemerényi (1970: 209). Sie ist ohne Modifikationen jedoch ebenso unhaltbar wie die beiden anderen Varianten der Ableitungstheorie, da $*_{s}$ hinter $u$-Laut möglicherweise zu balt. ${ }^{*} \check{s}$, aber auf jeden Fall zu aksl. $x$ vor velarem Vokal und $\check{s}$ vor palatalem Vokal geführt hätte. Seinen Ansatz *tūsñtī hat Szemerényi (1990: 241) übrigens später korrigiert. An dessen Stelle setzt er ein *tüso-kmt-ī mit einem adjektivischen Element *tūso- 'stark', das mit *tū-mo-'stark' in ahd. dūmo 'Daumen', *tū-ro'geschwollen' in lat. obtūrō zu vergleichen sei. Nach der Lautverschiebung sei im Germanischen der "Bindevokal" in *bussa-geschwunden ${ }^{13}$ und *-sh- zu -s- vereinfacht worden. Die germanische Form sei auch die Quelle der slavischen und nicht umgekehrt ${ }^{14}$, wie etwa Hamp (1973: 174) erwägt; und lit. tūkstantis sei aus *tūsantumgestaltet (Vaillant 1958: 647f.). Szemerényis revidierte Erklärung des Wortes 'tausend' ist aber nicht weniger problematisch als seine zunächst vertretene "Ableitungstheorie". Denn es fehlt eine Erklärung, wie man sich den Suffixablaut vorzustellen hat. Weiterhin ist die Annahme, das slavische Wort sei aus dem Germanischen entlehnt, lautlich mit Schwierigkeiten belastet (vgl. unten).

Die dritte These, nach der das Wort eine Entlehnung sei, ist auf den ersten Blick nicht von der Hand zu weisen, da es Beispiele für die Entlehnung von Zahlwörtern für höhere Zahlen gibt: z.B. alb. mijë 'tausend' aus dem Lateinischen, arm. hazar 'tausend' aus dem Iranischen, air. mīle 'tausend' aus dem Lateinischen (Lehmann 1986: 368). Wie später Szemerényi hat so Hirt (1896: 348) Entlehnung des slavischen Wor-

12 Pijnenburg (1989: 101f.) weist darauf hin, daß $h$ sonst nach Konsonant erscheint, und zwar in got. puthaurn 'Trompete' und in allen Präfixbildungen mit der Fortsetzung des Präfixes *uz-. Doch kann $h$ hier ebenso restituiert sein.

13 Meid 1967: 21. Als Parallele für den Schwund des Kompositionsvokals vor *- $h$-könnte man die Vorform

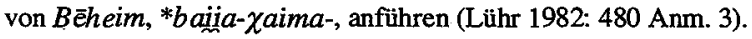

14 Ebenso Rix (1991: 225f.): Germ. *püsa-hundi setze ein *tuhso-(d)kmtih2 'starkes, dickes Hundert' fort und sei ins Baltische und Slavische entlehnt. 
tes 'tausend' aus dem Germanischen vermutet ${ }^{15}$. Doch bereitet bei dieser Annahme zum einen der im Slavischen auftretende Suffixablaut Probleme (Kiparsky 1934: 88); denn urgerm. * $p \bar{u} s u n d \bar{~}$ hätte ebenso wie urgerm. ${ }^{*} p \bar{u} s a n d \bar{i}$ eine Lautung mit aksl. $Q$ ergeben; zur Vertretung von urgerm. *an als aksl. $Q$ vgl. aksl. xodožbstvo 'Erfahrung' gegenüber got. handugs 'weise' (Stocki 1950: 55); zum anderen wäre urgerm. *d wohl als $d$ entlehnt worden, wodurch sich aksl. *tysgždi (lit. *tūsundi/*tūšundi) ergeben hätte (Kiparsky 1934: 88; Pijnenburg 1989: 100). Wenig wahrscheinlich ist auch die Annahme einer Entlehnung des germanischen Wortes aus dem Slavischen ${ }^{16}$ : Geht man von einem urslav. *tyxot'i aus, so wären zwar ${ }^{*} y$ durch $*_{\bar{u}}$ und ${ }^{*} Q$ durch $*^{*} a n$ substituierbar gewesen, aber für * $x$ wäre kaum ein $* s$ eingetreten, sondern sicher urgerm. * $\chi$ (vgl. aksl. $x y z ъ$ 'Hütte' < urgerm. * $\chi \bar{u} s a^{n}$ ). Und was ein urslav. *tyšęt'i als Ausgangspunkt angeht, so hätte in der Tat $*_{s}$ mit urgerm. ${ }^{*} s$ wiedergegeben werden können. Doch fragt sich, ob urslav. *e im Germanischen als *un erschienen wäre; es sei denn, man hätte das aus dem Slavischen entlehnte Wort 'tausend' nach dem germanischen Wort 'hundert' ( $\left.\chi u n đ a^{n}\right)$ umgebildet; vgl. demgegenüber aksl. kъnę(d)zb 'Fürst' < urgerm. *kuningaz (Arumaa 1964: 134). Eine weitere Variante der Entlehnungstheorie findet sich bei Uhlenbeck (1906: 300f.), nach dem die slavischen Formen aus dem Germanischen, die baltischen aus dem Slavischen entlehnt sind. Wie aber z.B. lit. túkstantis aus urslav. *tyxot ti, *tyšęt'i hervorgegangen sein soll, bleibt unklar $^{17}$.

Die vierte These, nach der das Wort 'tausend' einzelsprachlich innerhalb des Slavischen, Baltischen und Germanischen aus * $t \bar{u} s$ - und dem Wort 'hundert' zusammengesetzt ist, erscheint Pijnenburg (1989: 647) für aksl. tysęšti (Vaillant 1958: 647) zu Recht möglich: Nach den Regeln von Leskien (1990: 48) und Shevelov (1964: 188)

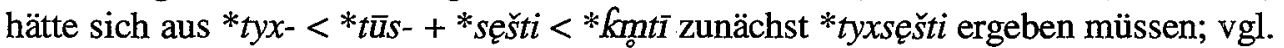
ksl. dъxnoti 'atmen' (zu lit. dùsti) mit $x$ vor Konsonant (n). Da jedoch in der Periode des Slavischen kein einziger Fall von - $x s-$ zu finden sei, könne bezeugtes tysęštti Repräsentant von urslav. *tyx + sęšti gewesen sein. Auch im Germanischen ist eine erst einzelsprachliche Zusammensetzung mit dem Wort 'hundert' denkbar, sofern der Schwund von anlautendem $* h$-im Kompositionshinterglied gemeingermanischen Alters ist (vgl. oben). Jedoch hält Pijnenburg (1989: 103) die baltischen Lautungen nicht für erst im Baltischen zustande gekommene Bildungen. Denn "eine erst baltische $\mathrm{Zu}$ sammensetzung *tūs-/tūšs- aus idg. *tūs- und šimti- aus idg. *Kmti- muß balt. *tūšimtiergeben." "Auch wenn man von einer Grundform mit Vollstufe-o ausgeht, also *tūs- + šamti-, kann nicht ohne weiteres auf lit. túkstantis, lett. tūkstoš, tũukstuotis geschlossen werden." Zu bemerken ist jedoch, daß im Altpreußischen ein Akk.Pl. tusimtons begegnet, der ohne weiteres das Wort 'hundert' enthalten kann; vgl. lit. šim̃tas, lett. simts

15 Hirt 1898: 340; Vaillant 1948: 184; Franck/Wijk 1949: 142.

16 Lexer 1876: 1590 (“wahrscheinlich"); Kawczyński 1888: 607f.; Sobolevskjj 1912: 480.

17 Nach Stang (1972: 59) stammt das Wort 'tausend' aus "unbekannter Quelle, das sich in nach-ieur. Zeit in einem bestimmten Sprachkreis verbreitet hat." 
(Vaillant 1958: 647; Comrie 1992: 792). Genau diese altpreußische Lautform wird bei der folgenden Erklärung eine entscheidende Rolle spielen.

\section{Ein neuer Erklärungsversuch}

\section{Die gemeinsame Vorform}

Überblickt man nun die germanischen und baltoslavischen Lautungen, so ist zweierlei von Bedeutung: Man hat Lautformen, die das Wort 'hundert' enthalten können, andere aber, wo dies nicht möglich ist. Zum zweiten ist der Suffixablaut, der sich, wenn man das Altpreußische mit einbezieht, in allen drei Sprachgruppen findet, auffallend. Betrachtet man zuerst diesen Suffixablaut, so ist die vielfach in der Forschung vertretene Auffassung, das Wort 'tausend' sei ursprünglich eine Zusammensetzung mit dem Wort 'hundert' gewesen und sekundär an die Partizipien des Präsens angeglichen worden ${ }^{18}$, nicht sehr überzeugend. Da keine semantischen Berührungspunkte zwischen Partizipien des Präsens und Zahlwörtern bestehen (Aitzetmüller 1991: 140), käme allenfalls eine rein formale Angleichung in Frage. Doch fehlt dafür die Ratio. Anders steht es, wenn man den umgekehrten Weg annimmt, also eine Partizipialbildung - wegen des Suffixablauts und der Lautfolge - $n t$ - kommt am ehesten eine solche Bildung in Frage ${ }^{19}$-, und die Angleichung an das Wort 'hundert' als sekundär betrachtet. Denn daß eine als Zahlwort für 'tausend' gebrauchte Bildung, die von Haus aus kein Zahlwort war, nach einem Zahlwort umgestaltet ist, erscheint weitaus einsichtiger. Die folgende Arbeitshypothese ist somit: Ein Partizip Präsens, das substantiviert worden sein müßte, bildet im Germanischen und Baltoslavischen die Basis des Wortes 'tausend'. Da das Wort 'tausend' auf das Wort 'hundert' beziehbar war, konnte es nach dem Wort 'hundert' umgebildet werden.

Trifft diese Annahme zu, so ist als nächstes nach einem solchen Partizip Präsens als Ausgangsform des Wortes 'tausend' zu suchen, von der aus sich die Abweichungen

18 Z.B. Vondrák 1924: 423 (als Möglichkeit); Comrie 1992: 792f.: Die Fortsetzung von *tü(s)-Kmat- sei im Baltischen und Slavischen sekundär zum Partizip umgedeutet worden. Für das Nebeneinander von urslav. *tysęt- und *tysot- verweist er auf aksl. gorešst-, gorošt- 'brennend'; und urbalt. *tūšant- sei als Partizip interpretiert worden, indem der Präsensstamm *tūs $a$ - mit einem neuen Präsensstamm ${ }^{*} t \bar{u}$-sta- vermischt wurde. In ähnlicher Weise hat bereits Endzelin (1923: 366) für die "litauisch-lettische Ursprache" ein *tū(s)-samt- angesetzt, das, "sobald es nicht mehr als Kompositum empfunden wurde, volksetymologisch einem Partizip *tūšant- (aus ide. $t \bar{u}-s k o-n t$-) angeglichen" wurde. Auf den Präsensstamm urbalt. *tū̌s $a-$ deute dabei noch indirekt lett. $t u ̄ s k t$ (neben $t u ̈ k t$ ) 'schwellen, fett werden'. Weiterhin sei neben dem Präsensstamm *tūša- <* $t \bar{u}-s k \bar{o}$ ein gleichbedeutender Präsensstamm *tū-sta- aufgekommen, deren Kontaminationsprodukt *tūšta- die Bildung eines Partizips *tūštant- 'tausend' ermöglicht habe. $-k$ - in lit.

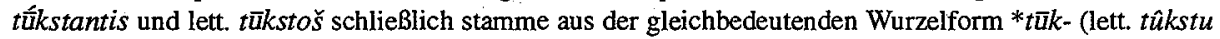
'ich schwelle, werde fett'). Vgl. auch Osthoff/Brugmann 1890: 11; Walde/Pokorny 1930: 707; Fraenkel 1932: 98. Nach Comrie (1992: 792) ist ebenso $k$ von der Wurzel *tuk- (lett. tûkstu 'werde fett') bezogen, - $s$ - aber von den Verben auf $-s t a-$.

19 Theoretisch könnte ein Vertreter des "amphidynamischen" Typs *uék-ont-s (vgl. griech. $\varepsilon \kappa \omega ́ v)$, *uk-nt-és (ai. uśatás) 'wünschend' vorliegen. Doch ist dieser Typ in keiner Einzelsprache lebendig (Rix 1976: 123, 234). 
im Germanischen, Baltischen und Slavischen am einfachsten erklären lassen. Für die Rekonstruktion dieser Form spielt das aus dem Baltischen entlehnte finn. tuhat, Gen. tuhannan 'tausend' eine Rolle. Finn. $-h$ - steht hier höchstwahrscheinlich für balt. $*_{-}{ }_{-}-$ (Vorform *tušamte ${ }^{20}$ ) und nicht für $*_{-s ̌ t}{ }^{-},{ }^{*}{ }_{-s t}$ (Stang 1966: 282) $)^{21}$, und balt. $*_{-s}-$ kann auf uridg. ${ }^{*} K,{ }^{*} k s^{22}$ oder ${ }^{*} s$ (hinter $* \bar{u}$ ) zurückgehen, Lautwandel, die bekanntlich nicht allgemein durchgeführt sind (Stang 1966: 91ff.). Wenn aber das Finnische für das Baltische einen $s$-Laut erweist, muß die $s t$-Verbindung im baltischen Wort 'tausend' eine Neuerung sein. Als Transponate für das Wort 'tausend' ergeben sich so, wenn man mögliche Angleichungen an das Wort 'hundert' zunächst unberücksichtigt läßt, die Partizipialstämme vorurslav. *tūkKont-, *tūkno $n t-$ und *tūksont-, *tūksnt-, vor-

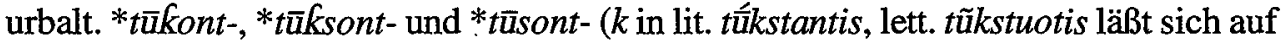
sekundären Einschub vor Sibilant zurïckführen; vgl. alett. tuustosch-; Stang 1966: 109) und vorurgerm. *tūsont-, *tūsnt $t$. Für das Germanische ist daran zu erinnern, daß altes inlautendes ${ }^{*}-s k$ - erhalten geblieben wäre und so nicht vorliegen kann. $*_{-s-}$ vertritt allenfalls eine ursprüngliche Lautfolge $*_{-s-} \chi$-, die aber nur von einer Zusammensetzung mit dem Wort 'hundert' und nicht von einer Partizipialbildung herleitbar ist. $\mathrm{Zu}$ den Transponaten hat man auch die sich aus apreuß. tusimtons ergebende Vorform zu stellen (Shevelov 1964: 91). Diese ist, wenn man $m$ als sekundäre Angleichung an das Wort 'hundert' betrachtet, entweder als *tūkntont, *tūksñt- oder *tūsntanzusetzen. Vergleicht man nun diese Transponate miteinander, so erscheinen sie zu ähnlich, als daß sie unabhängig voneinander zustande gekommen sein können. Der Unterschied betrifft lediglich den auf $* \bar{u}$ folgenden Konsonantenstand: vorurslav. und vorurbalt. $* K$, vorurslav. und vorurbalt. $* k s$, vorurgerm. und vorurbalt. *s. Um nun zu entscheiden, welches die tatsächliche Vorform darstellt, ist nicht nur zu beachten, wie $*_{K}, *_{K} s$ und $*_{s}$ im Germanischen und Baltoslavischen vertreten sind. Auch müssen mögliche Angleichungen an die Fortsetzung von $* k$ des Wortes 'hundert' in die Überlegungen mit einbezogen werden. Die Formen mit *K und $* k s,{ }^{*} t \bar{u} K o n t-,{ }^{*} t \bar{u} K_{o} t-$ bzw. $* t \bar{u} k s o n t-,{ }^{*} t \bar{u} k s n g t-$ scheiden aus, weil sie im Germanischen zu Lautungen mit * $\chi / g$ bzw. * $\chi s$ geführt hätten und in * $p \bar{u} s u n d-$, * $p$ üsand- nicht das Wort 'hundert' eingedeutet sein kann. Übrig bleibt so nur der Partizipialstamm *tūsont-, *tūsñt-. Ist dieser Stamm der richtige Ansatz, kann -s- im Slavischen auf Angleichung an das Wort 'hundert' (aksl. sbto) beruhen. Einer besonderen Erklärung bedarf jedoch -st- im Baltischen, eine Lautfolge, die, wie sich zeigen wird, mittelbar ebenso mit dem Wort 'hundert' in Zusammenhang gebracht werden kann.

20 Itkonen/Joki/Peltola 1975: 1374. Vgl. finn. hanhi 'Gans' < balt. *šanše. Zuweilen steht finn. $h$ in Lehnwörtern jedoch auch für st in der Lautfolge str, wie finn. ihra 'Speck' (an. istra 'Fetthülle der Eingeweide') zeigt (Hakulinen 1957: 34f.).

21 Aitzetmüller 1991: 140. Arumaa (1985: 199) findet $\check{z}$ bei der wolgafinnischen Entsprechung auffallend. Doch entspricht auch sonst wolgafinn. $\check{z}$ einem finn. $h<* \check{s}$; vgl. mordwin. Erza ožo, tscheremiss. užar 'gelb' zu finn. viha 'Zorn, Haß' (ai. vișá-, av. vīsa- 'Gift') (Hinweis von R.-P. Ritter). 
Demnach wäre also im Germanischen die reguläre Form fortgesetzt. Dies verträgt sich mit einer möglichen Hypothese über das Ursprungsgebiet des Wortes 'tausend'. Denn hält man an einer germanisch-baltoslavischen Isoglosse fest, so gibt es eventuell Hinweise darauf, daß das Wort bei den Vorfahren der Germanen aufgekommen ist und sich von da aus zu den Vorfahren der Balten und Slaven verbreitet hat Vorurgermanisch, Vorurbaltisch und Vorurslavisch bildeten damals noch ein "Kommunikationskontinuum". Es handelt sich um den Ausgang und um die Verbalwurzel des Partizips bei der Vorform des Wortes 'tausend'.

Wegen des $i$-Lautes im Ausgang (vgl. got. pūsundi, Pl. pūsundjos, aksl. tysěšti, tysQšti) dürfte morphologisch am ehesten ein substantiviertes Femininum auf $*_{-\bar{\imath}}$ (vgl.

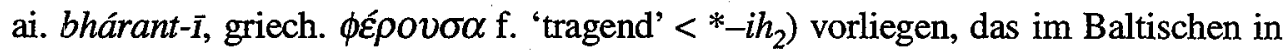
Angleichung an lit. dešimtìs, -iẽs f. 'zehn' (aksl. desętb) nach den $i$-Stämmen flektiert wurde (lit. dial. túkstantis, -ies f.; lit. túkstantis, -čio m. nach dem Vorbild von šim̃ntas 'hundert'; Fraenkel 1910: 202). Ein substantiviertes Partizip auf $*_{-\bar{\imath}}$ ist jedoch innerhalb der germanischen und baltoslavischen Sprachen nur im Germanischen nachweisbar; vgl. got. hulundi 'Höhle', Frauenname ahd. Purgunt (ai. brhatī, av. bərəzaitī f. 'hohe, starke', gall. Brigantēs, air. Brigit ${ }^{23}$ ). Auch die der Partizipialbildung *tūsontī,

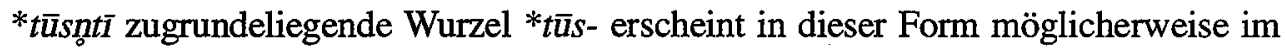
Germanischen: Aisl. pústr m. 'Feindseligkeit, Zorn' im Sinne von '(vor Zorn) Angeschwollensein', nostfries. dūst 'Troddel', nnorw. tūst 'Büschel, Haarzotte, Quaste', tūsta 'Büschel, Knoten, Bündel, Baum mit buschiger Krone', nisl. pūsta 'Haufen, Masse' können auf ein *tūs- 'schwellen' $+t$ zurückgeführt werden ${ }^{24}$. In der Form *tuH-s- stellt sich die Wurzel zu der in ai. táviṣī 'Kraft, Stärke', aav., jav. tauuǐš̄ 'Kraft, Körperkraft' auftretenden Wurzelform *teun $\partial_{2} s$ - (Mayrhofer 1992: 639). Sofern diese Wurzel, was allerdings nicht weiter belegt werden kann, auch als Verbalwurzel verwendbar war und von ihr Partizipien gebildet wurden, ergibt sich als Grundbedeutung von *tūsñtī, *tūsontī die Bedeutung 'Anschwellende (Menge); Anschwellung, Haufe'25; vgl. die Bedeutung 'Menge' von aksl. tъma (russ. tъmá) '10 000', das wohl nicht von lit. tùm(s)tas 'Haufen, Menge', (Ašmenà) tumstas '1000' (Fraenkel 1965: 1136) zu trennen ist (Aitzetmüller 1991: 141) ${ }^{26}$.

23 Brugmann 1913/14: 305ff.; Meid 1967: 171.

24 Holthausen 1930: 257. Ob lett. $t \bar{u} s k a$ 'Geschwulst', $t \bar{u} s k$ 'is 'Wassersucht' ebenso von der Wurzel *tūsherstammen, ist unsicher, da die lettischen Wörter eine $s k$-Ableitung von lett. tûkt 'schwellen' sein können (Pokorny 1959: 1084).

25 Eine mit dem Wort 'tausend' vergleichbare Bildung hat man in toch. B tumane ( $\left.-t^{\prime} m a \bar{n} e\right)$, tmāne (-tmane), A tmām 'zehntausend' gesehen und dies als Substantivierung eines von der unerweiterten Wurzel *teun $\mathrm{H}_{2}$ 'stark sein' abgeleiteten mediopassivischen Partizips 'das, was angeschwollen ist' betrachtet (Windekens 1941: 143; kritisch dazu Winter 1992: 127). Auch eine Entlehnung aus dem Iranischen wurde erwogen (Windekens 1976: 642; Isebaert 1980, 102f., 118). Bei dem tocharischen Wort handelt es sich jedoch um ein aites Kultur- und Wanderwort, das sich in vielen asiatischen Sprachen, so - außer im Tocharischen - im Persischen, Türkischen, Mongolischen, Tungusischen, Chinesischen, findet und dessen Herkunft bis heute nicht sicher geklärt ist (Hinweis von K.T.Schmidt; vgl. Doerfer 1965: 641f.). 


\section{Aisl. púshund, aisl., runenschwed. pūshundrað}

Was nun die Sonderentwicklungen im Germanischen, Slavischen und Baltischen angeht, so erklärt sich $-h$ - in aisl. púshund, aisl., runenschwed. pusshundrað als Angleichung an das Wort 'hundert' (vgl. aisl. púshund, aisl., runenschwed. pūshundrað mit aisl., aschwed. hund-rap), sofern als Vorform tatsächlich allein ein $s$-haltiges *tūsnntī $\left({ }^{*} t \bar{u}\right.$ sontī $)$ anzusetzen ist. Da das Wort 'hundert' und das Wort 'tausend' die übereinstimmende Lautfolge *-und-aufweisen, liegt im Germanischen die Eindeutung von 'hundert' besonders nahe.

\section{Aksl. tysęšti, tysǫšti}

Anders verhält es sich im Slavischen, da die auslautende Lautgruppe abweicht: *tyxot' $i,{ }^{*}$ tyšęt'i gegenüber aksl. sbto, wobei das slavische Wort 'hundert' lautgesetzlich nicht aus der urindogermanischen Vorform * Kmotóm herleitbar ist. Doch erscheint die zu erwartende Lautung *sęto, die, von der Umbildung nach der Nom./Akk.-Endung der neutralen $o$ - und $s$-stämmigen Substantive im Slavischen und nach den $a$ stämmigen Maskulina im Baltischen abgesehen, lit. šim̃tas, lett. sìmts entspricht ${ }^{27}$, in slav. *tysęt'i (Aitzetmüller 1991: 140). Daher liegt der Schluß nahe, daß auch das Slavische die lautgesetzliche Fortsetzung des urindogermanischen Wortes 'hundert' besessen hat und diese in das Wort 'tausend' eingedeutet wurde ${ }^{28}$. Ebenso zeigt apreuß. tūsimtons diese Umbildung. Aus diesem Grunde ist möglicherweise bereits in der Vorstufe des Baltoslavischen die schwundstufige Form *tūsnntī nach dem Wort 'hundert' umgebildet worden (Hirt 1896: 347). Verfolgt man nun die Entwicklung im Slavischen weiter, so dürfte von *tysęt'i aus das * $s$ auch in die danebenstehende, ursprünglich $o$-stufige Form *tyxot' $i$ eingedrungen sein und so ein *tysot'i ergeben haben.

Gesetzt den Fall, daß zu dieser Zeit im Slavischen noch die lautgesetzliche Kontinuante des Wortes 'hundert', *sęto, vorhanden war, so gewinnt man möglicherweise weiterhin eine Erklärung für die im Slavischen abweichende Lautform des Wortes

26 Sadnik/Aitzetmüller 1955: 323t. Anders Vasmer 1958: 162: Die Bedeutung von aksl. $t ъ m a$ sei Lehnübersetzung aus turkotatar. tuman 'zehntausend, Nebel' (Rosenkranz 1955: 107). Fraenkel (1932: 98) verweist weiterhin auf poln. chmura und griech. vह́ $\phi \circ \varsigma$ 'Wolke', Wörter, die ebenfalls große Zahlen, Unmengen bezeichnen.

27 Uridg. *m kann im Frühurslavischen zwar auch als *um vertreten sein, doch stimmen das Baltische und Slavische hinsichtlich der Vokalqualität der Fortsetzungen von uridg. *m und *n sonst überein; vgl. aksl. doti, lit. dùmti 'wehen, blasen', aksl. Präs. ḑmo, apreuB. dumsle 'Hornblase' (Arumaa 1964: 135). Zudem erscheinen sonst palatale Reflexe von $*_{0}$ und $*_{0}$ hinter der Fortsetzung von Palatalen (Shevelov 1964: 86ff.; Comrie 1992: 784).

28 Die Lautfolge *ty- war möglicherweise volksetymologisch auf urslav. *tyjō 'werde fett' (aruss., russ.-ksl. $t y t i$, tyju ' $\pi \alpha i ́ v \varepsilon \sigma \theta \alpha t^{c}$, ukr. týty, tyju, skr. tïti, tîjêm, tschech. týti, tyji, poln. tyć, tyję, osorb. tyć usw.; Vasmer 1958: 162) zu beziehen und *tysot' $i$ so als 'fettes, großes Hundert' = 'Tausend' zu interpretieren (Vondrák 1924: 132, 423). Demgegenüber betrachtet Kawczyński (1888: 607) eine Bedeutungsentwicklung von 'fette, große Zahl' zu 'tausend' als eine der "kühnsten" "Bedeutungsverschiebungen", "auf welche man je verfallen ist." Doch wird der eben erwogene Bedeutungsansatz 'fettes, großes Hundert'> 'Tausend' als volksetymologische Deutung von *tysęt'i verstanden. 
'hundert' (aksl. şto usw.), dessen velarer Vokal gegenüber dem palatalen Vokal im Baltischen (lit. šiñtas, lett. simts) entgegen den Lautregeln ist. Die Erklärung vollzieht sich in drei Schritten: In gleicher Weise wie im Slavischen *tyset $t i$ auf die Form * sęto 'hundert' bezogen werden konnte, bestand die Möglichkeit, nach der ursprünglich $o$-stufigen Form *tysot' $i$ eine ablautende Variante *soto 'hundert' zu bilden ${ }^{29}$. Weiterhin war es möglich, daß ebenso wie *e in *sęto als antekonsonantische Vertretung der Reduktionsstufe ${ }^{*} b m$ auffaßbar war, $* g$ in ${ }^{*}$ s $Q$ to als antekonsonantische Vertretung der Reduktionsstufe ${ }^{*}$ bm betrachtet wurde. Trat nun in einem solchen synchron als Vertretung von ${ }^{*} \mathrm{~b} m$ geltenden ${ }^{*} Q$ eine durch Schwachtonigkeit bedingte Entnasalierung ein, so war das Ergebnis ${ }^{*_{\boldsymbol{B}}}$, wie es in dem slavischen Wort 'hundert' (aksl. şto usw.) auftritt. Ein Nebeneinander von verwandten Formen mit $*_{Q}$, $*_{\mathfrak{B}}$ und $*_{\boldsymbol{B}}+$ Nasal, deren unterschiedliche Laute für damalige Sprecher mit Schwachtonigkeit in Verbindung gebracht werden können, begegnet im Slavischen auch sonst, und zwar in dem Nominalpräfix $s Q$-, in den Verbalpräfixen $s \not n$ - und $s$ - 'zusammen' und in der Präposition $s b$ 'mit'. Vielleicht hat der für das Wort 'hundert' erwogene Wandel von $*_{Q} \mathrm{zu}{ }^{*} \boldsymbol{b}$ aber sogar in einem weiteren Zahlwort eine unmittelbare Parallele: Entspricht aksl. vъtorı 'zweiter' den Wörtern lit. añt(a)ras, ai. ántara-, got. anpar, so könnte auch hier ${ }^{*} Q$ der Vorform *otorı (Arumaa 1964: 135; Schmalstieg 1971: 139f. $)^{30}$ als Vertretung einer Reduktionsstufe $\left({ }^{*} b n\right)$ empfunden und im Schwachton zu ${ }^{*} b$ entnasaliert worden sein. Im Falle des Wortes 'hundert' ist aksl. sъto jedenfalls auf Kosten der lautgesetzlichen Form verallgemeinert worden ${ }^{31}$.

\section{Lit. túksstantis, lett. tũ kstuotis}

Noch problematischer als im Slavischen liegt der Fall im Litauischen und Lettischen. Denn hier hat man bei dem Wort 'tausend', wie bemerkt, ein -st-, das weder von der durch das Finnische geforderten Vorform mit *-š- noch mit der angenommenen partizipialen Vorform ${ }^{*} t \bar{u} \operatorname{son} t \bar{i}\left({ }^{*} t \bar{u} s n t \bar{\imath}\right)$ vereinbar ist und auch nicht mit dem Anlaut des Wortes 'hundert' (lit. šiñtas, lett. sìmts) übereinstimmt. Doch möglicherweise hat das Wort 'hundert' auch bei der Umbildung des litauisch-lettischen Wortes 'tausend' eine Rolle gespielt. Überlegt man zunächst, in welcher Art von Zahlwort ein - $t-$

29 Vgl. Shevelov 1964: 91: "*simtom obtains a parallel form *sumtom under the influence of alternating -imt: -umt- (later -et- : - $Q t$-) in *tū(s)simt-". Doch geht Shevelov, wie sein Ansatz *tū $(s) k m t-i \bar{a}$ zeigt, für das Wort 'tausend' offensichtlich von einer alten Zusammensetzung mit dem Wort 'hundert', *tūs- + *kmt- (zu aruss., russ.-ksl. tyti 'fett werden') aus $(141,181)$.

30 Anders z.B. Meillet 1895: 329: *n-; Brugmann 1909: 169: *u-; Pedersen 1905: 395: zu ai. vítaras 'weiter führend' (Vasmer 1950: 237 mit weiterer Literatur).

31 Barschel (1967: 451) wendet sich zu Recht entschieden gegen Arumaas (1964: 130) Auffassung von aksl. ssto als iranischem Lehnwort - iran. $a$ wird nicht durch slav. $\mathbf{b}$ oder b wiedergegeben (Arumaa: urslav. *sbmto-), und ein Ansatz iran. * sutam bzw. *sitam sei für die slavische Form nicht gerechtfertigt. Nach Barschel ist nasalloses sbto erst auf slavischem Boden entstanden, und zwar sei vor dem Abfall des Auslautskonsonanten *şmtom zu *sbtom dissimiliert worden (ebenso bereits Vondrák 1924: 147, 423; Shevelov 1964:91). Wenig einsichtig ist Szemerényis (1960: 65) Annahme, daß eine frühere Form *sinto ${ }^{n}$ durch die Endung der ehemaligen Dekadenbezeichnungen *-sb (z.B. *newinsъ( $n)$ 'neunzig') umgestaltet sei. Weiterhin ist ein Ansatz uridg. * Kutom für aksl. şto nicht gerechtfertigt (Comrie 1992: 784). 
zu erwarten ist, so stößt man unweigerlich auf das Ordinale; vgl. lit. trẽčias 'dritter' (< *-tia-) gegenüber trỹs 'drei', ketvir̃tas 'vierter' gegenüber keturi 'vier' usw. Während sich in diesen Zahlen Kardinale und Ordinale durch das Fehlen bzw. Vorhandensein von $-t$ - unterscheiden, gibt es ein Wort, das in der gleichen Lautform sowohl als Kardinale als auch als Ordinale fungiert, und zwar genau das Wort 'hundert': lit. šiñntas, lett. simts 'hundert', 'hundertster', ein Zusammenfall, der dadurch bedingt ist, daß die Fortsetzung von *-om in *Krotóm als neutrale Endung aufgefaßt wurde, das Neutrum beim Substantiv aber im Litauisch-Lettischen aufgegeben und zumeist zum Maskulinum umgebildet worden ist (Stang 1966: 179). Ähnliche lautliche Übereinstimmungen zeigen sich beim Kardinale und Ordinale des Wortes 'tausend': lit. $t \bar{u} k$ stantis, lett. tũkstuotis Kardinale und lit. túkstantysis (Kurschat), túkkstantas (Jablonskis), túkstantinis, lett. tũkstuošais Ordinale. Da also die Kardinalia und Ordinalia der Wörter 'hundert' und 'tausend', von den Endungen beim Wort 'tausend' abgesehen, jeweils identisch sind, liegt der Schluß nahe, daß das Wort 'tausend' in der Vorstufe des Litauisch-Lettischen durch den Einfluß des Wortes 'hundert' zu seinem $t$-Laut gekommen ist ${ }^{32}$. Für diese Annahme spielen nun die im Litauischen in älteren Grammatiken angegebenen Ordinalia túkstinis und $t \bar{u} k s t a ̀ s i{ }^{33}$, die keine Entsprechung beim Kardinale haben, eine Rolle. Folgende Entwicklung erscheint denkbar: Neben dem Kardinale *tūsantis' 'tausend' stand ein Ordinale *tūsantas 'tausendster' mit adjektivischer Flexion; zu den Ausgängen vgl. lit. dešimtìs 'zehn' neben dešim̃tas 'zehnter'. In Verbindung mit Substantiven wurde das Ordinale *tūsantas zu *tūstas (lit. tūkstàs-is, túkst-inis) verkürzt. Eine derartige Verkürzung hat in anderen indogermanischen Sprachen bei Ordinalia Parallelen (z.B. urgerm. *tegunpan- > ae. Lindisfarne teigða <-tegða in mehrsilbigen Wörtern ${ }^{34}$ ) und kommt auch im Baltischen im Falle von Silben, die aus Vokal und Nasal bestehen, vor (z.B. vargõninkas neben vargõnininkas 'Organist' mit Suffix -ininkas ${ }^{35}$ ). Für das Litauisch-Lettische gab es im Falle des zweisilbigen Ordinale 'tausendster' jedoch das Vorbild *simtas 'hundertster'. Was die weitere Entwicklung des Wortes 'tausend' im Baltischen betrifft, so ist anzunehmen, daß die längere Form des Ordinale, $* t \bar{u} s a n t a s$, weiter bestand. Unter dem Einfluß von *tūsantas und den Vorformen der Ordinalia lit. septiñtas, lett. septîtais 'siebter', ašttuñtas, lett. dial. astūt(ai) $s^{36}$ wurde *tūstas zu *tūstantas erweitert; vgl. mndd. twelftende neben twelfte 'zwölfter' (Lasch 1914: 210) wohl nach dem Vorbild von teinde 'zehnter', achteste, teinste, afries. achtunda (Lloyd/Springer 1988: 123). Schließlich - wegen des Gleichlauts von *šimtas 'hundert, hundertster' und *dešimtis

32 Zur lautlichen Beeinflussung von Ordinalia durch Ordinalia, die durch eine Rechenoperation aufeinander beziehbar sind, vgl. Winter (1969: 38), der auf die nach 'zehnter' umgebildeten Ordinalia griech. arkad.

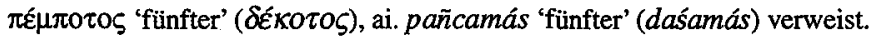

33 Kurschat 1876: 265; Senn/Salys 1963: 731; Endzelin 1971: 185.

34 Sievers/Brunner 1965: 256; Ross/Berns 1992: 632.

35 Senn 1966: 319; Endzelin 1971: 36, 70.

36 Zur Erklärung der Formen auf *-nt- siehe Stang 1966: $283 f$. 
'zehn', *dešimtas 'zehnter' - trat neben das Ordinale *tūstantas ein Kardinale *tūstantis ${ }^{37}$.

\section{ZUSAMMENFASSUNG}

Sind die angenommenen Umbildungen des Wortes 'tausend' im Germanischen und Baltoslavischen zutreffend, so kann man in beiden Fällen von einer Semantifizierung der Lautform des Wortes 'tausend' sprechen. Denn in die Fortsetzungen der postulierten Grundform *tūsontī, *tūsntī 'Anschwellung, Haufe', der Substantivierung eines Partizip Präsens ('Anschwellende [Menge]'), wurde - mehr oder weniger offensichtlich - das Wort 'hundert' eingedeutet. Der vorgestellten Deutung des Wortes 'tausend' am nächsten kommt Aitzetmüllers (1991: 140) Behandlung dieses Wortes. Auch für ihn sind als Grundformen *tūsontī, *tūsntī anzunehmen, die nach dem Wort 'hundert' umgebildet wurden. Doch sieht er, wie bemerkt, in diesen Bildungen keine Partizipien, sondern Adjektive mit einem - nt- in elativierender Funktion.

Ausgangspunkt für die oben gegebene Diskussion war die Überlegung, daß sich - wegen des für ein Partizip Präsens typischen Suffixablauts *-ont-, *-nt- - als Grundform des Wortes 'tausend' eher ein Partizip anbietet als ein Zahlwort. Denn die Annahme, daß ein Partizip, das als Zahlwort fungiert, nach einem Zahlwort umgebildet wird, ist plausibler als der umgekehrte Weg. Von den für das Wort 'tausend' in Frage kommenden Transponaten *tūkont-, *tūknt- und *tūksont-, *tūksnt- (vorurslav., möglicherweise auch vorurbalt.) und *tūsont-, *tüsñt- (vorurgerm., eventuell auch vorurbalt.) wurden die im Germanischen nahezu unverändert fortgesetzten Lautungen *tūsont-, *tūsnt- als Grundformen des Wortes 'tausend' betrachtet, weil sich daraus die einzelsprachlichen Vertretungen mitsamt ihren Umbildungen nach dem Wort 'hundert' am einfachsten ableiten lassen. Lag in den drei Sprachzweigen keine lautgesetzliche Vertretung von *tūsont-, *tūsnt- vor, so ist im Falle des Germanischen und Altpreußischen die Eindeutung des Wortes 'hundert' am sichtbarsten: vgl. aisl. púshund, aisl., runenschwed. pūshundrað mit aisl., aschwed. hund-rap; apreuß. tüsimtons mit lit. šiñntas, lett. simts. Die Entsprechung des baltischen Wortes 'hundert', urslav. *sęto (mit Umbildung nach der Nom./Akk.-Endung der neutralen $o$ - und $s$ stämmigen Substantive), die entgegen dem bezeugten Wort (aksl. sbto) den regulären palatalen Vokal aufweist, dürfte ebenso im Slavischen vorgelegen haben, wie aksl. tysęšti (anstelle von *tyšešsti) deutlich macht. Von tysęšti ist $-s-$ wohl ferner auf die Vorform *tyxQšti von aksl. tysošti übergegangen. Trifft dies zu und hat zu dieser Zeit

37 In ähnlicher Weise nimmt Gauthiot (1904: XIX) eine Übertragung von st aus dem Ordinale täkstas an; doch geht er für die Vorform von einer selbständigen Bildung *tüs-to- aus, die unmittelbar vom Vorderglied *tūsmit dem *-to- der Ordinalia gebildet sei. Leumann (1942: 128) kritisiert an dieser Auffassung "die Überspringung des Elementes ' 100 '", worin ihm zweifellos zuzustimmen ist. Seiner Meinung nach ist tūkstas eine verkürzte Ableitung vom Kardinale tūkstantis, "natürlich in Anlehnung an šim̃tas ' 100 ', wobei schon šim̃tas als Ordinale leicht möglich war, weil es an die regulären Ordinalia auf -tas der kleineren Zahlen anklang." 
die auch für das Slavische zu postulierende Form *sęto 'hundert' existiert, könnte aus tysošti eine mit *sęto ablautende Variante *soto erschlossen worden sein, wodurch sich eventuell eine Erklärung für die im Slavischen abweichende Lautform des Wortes 'hundert' ( $s$ bto ) ergibt (vgl. oben). Was schließlich die noch zu erklärenden Formen im Baltischen betrifft, so sind durch Einflußnahme des Wortes 'hundert', das im Baltischen nicht nur als Kardinale, sondern auch als Ordinale fungiert, möglicherweise weiterhin die Lautformen lit. túkstantis, lett. tũkstuotis 'tausend' deutbar. Die bezeugten Ordinalia lit. túkstinis und tūkstàsis könnten auf ein neben dem Kardinale *tūsantis 'tausend' vorhandenes Ordinale *tūsantas 'tausendster' weisen, das in Verbindung mit Substantiven nach dem Vorbild von * šimtas 'hundertster' zu *tūstas (lit. tūkstàs$i s$, túkst-inis) verkürzt wurde. Die längere Form *tūsantas müßte daneben weiter existiert haben, *tūstas nach deren Vorbild und anderer Ordinalia mit der Lautfolge -ntas zu *tüstantas erweitert worden ${ }^{38}$ und schließlich neben $* t \overline{u s t a n t a s}$ ein Kardinale *tūstantis getreten sein. Gegenüber dem Slavischen wäre dabei im Baltischen im Falle der Form mit ursprünglich $o$-stufigem Suffix also nicht die ganze Lautform des Wortes 'hundert' in das Wort 'tausend' übernommen, sondern nur ein allein für das litauisch-lettische Wort 'hundert' charakteristischer Lautstand: Im Zuge der Aufgabe des Neutrums beim Substantiv war der Ausgang *-tas des Kardinale (gegenüber *-tom von * Kmónóm) mit dem des Ordinale zusammengefallen.

Mit den angenommenen Umbildungen nach dem Wort 'hundert' kann das Wort 'tausend' im Germanischen und Baltoslavischen tatsächlich als Isoglosse betrachtet werden.

\section{Literaturverzeichnis}

Aitzetmüller 1991: R. Aitzetmüller, Altbulgarische Grammatik als Einführung in die slavische Sprachwissenschaft, ${ }^{2}$ Freiburg i. Br. (Monumenta linguae slavicae dialecti veteris. Fontes et dissertationes 30 )

Arumaa 1964. 1976. 1985: P. Arumaa, Urslavische Grammatik. Einführung in das vergleichende Studium der slavischen Sprachen, I: Einleitung, Lautlehre (I. Teil: Vokalismus, II. Teil: Betonung). II: Konsonantismus. III: Formenlehre, Heidelberg

Barschel 1967: B. Barschel, Besprechung von: Arumaa 1964, Wissenschaftliche Zeitschrift der Martin-Luther-Universität Halle-Wittenberg, Gesellschafts- und sprachwissenschaftliche Reihe 16, 449-451

Bengtson 1987: J.D. Bengtson, Notes on Indo-European "10", "100", and "1000", Diachronica 4, 257-262

Bräuer 1961: H. Bräuer, Slavische Sprachwissenschaft, I: Einleitung, Lautlehre, Berlin (Sammlung Göschen 1191/1191a/1191b)

38 Auch die Annahme einer Kontamination wäre möglich. 
Brugmann 1897. 1906. 1911: K. Brugmann, Vergleichende Laut-, Stammbildungsund Flexionslehre der indogermanischen Sprachen..., I. II, 1. II, 2, 1, ${ }^{2}$ Straßburg

- 1909: Gotisch baírōs und der Dual der Indogermanen, Indogermanische Forschungen $24,165-173$

- 1913/14: Zur nominalen Stammbildung der germanischen Sprachen, Indogermanische Forschungen 33, 300-313

Bugge 1888: S. Bugge, Etymologische Studien über germanische Lautverschiebung, Beiträge zur Geschichte der deutschen Sprache und Literatur 13, 311-339

Comrie 1992: B. Comrie, Balto-Slavonic, in: Gvozdanović 1992: 717-833

Doerfer 1965: G. Doerfer, Türkische und mongolische Elemente im Neupersischen, II, Wiesbaden

Endzelin 1923: J. Endzelin, Lettische Grammatik, Heidelberg (Indogermanische Bibliothek 5.1)

- 1971: J. Endzelinns' Comparative Phonology and Morphology of the Baltic Languages, translated by W.R. Schmalstieg/ B. Jēgers, The Hague/Paris (Slavistic Printings and Reprintings 85)

Feist 1939: S. Feist, Vergleichendes Wörterbuch der Gotischen Sprache, ${ }^{3}$ Leiden

Fraenkel 1910: E. Fraenkel, Beiträge zur griechischen Grammatik, Zeitschrift für vergleichende Sprachforschung 43, 193-219

- 1932: Zur tocharischen Grammatik, Indogermanische Forschungen 50, 97108

— - 1965: Litauisches etymologisches Wörterbuch, II, Heidelberg

Franck/Wijk 1949: J. Franck/N. van Wijk, Etymologisch woordenboek der nederlandsche taal, ${ }^{2}$ den Haag

Gauthiot 1904: M. Gauthiot, [Zu lit. túkstantis], Bulletin de la société de linguistique de Paris 13, XIX

Gvozdanović 1992: J. Gvozdanović (Ed.), Indo-European Numerals, Berlin/New York (Trends in Linguistics: Studies and Monographs 57)

Grimm 1868: J. Grimm, Geschichte der deutschen Sprache, I, ${ }^{3}$ Leipzig

Hakulinen 1957: L. Hakulinen, Handbuch der finnischen Sprache. Aus dem Finnischen übersetzt..., I, Wiesbaden

Hamp 1973: E.P. Hamp, North European "1000", in: C. Corum / T.C. Smith-Stark / A. Weiser (Ed.), Papers from the Ninth Regional Meeting [of the] Chicago Linguistic Society, April.13-15, 1973, Chicago, 172-178

van Helten 1900: W. van Helten, Zu den malbergischen Glossen..., Beiträge zur Geschichte der deutschen Sprache und Literatur 25, 225-542

- 1905: Zum germanischen Zahlwort, Indogermanische Forschungen 18, 84 126 
Hirt 1896: H. Hirt, Akzentstudien, 1: Germ. got. $p \bar{u} s u n d i$, Indogermanische Forschungen 6, 344-349

- 1898: Grammatisches und Etymologisches, Beiträge zur Geschichte der deutschen Sprache und Literatur 23, 288-357

Holthausen 1930: F. Holthausen, Wortdeutungen, Indogermanische Forschungen, 48, 254-267

Isebaert 1980: L. Isebaert, De Indo-Iraanse bestanddelen in de Tocharische woordenschat. Vraagstukken van fonische productinterferentie, met bijzondere aandacht voor de Indo-Iraanse diafonen $a, \bar{a}$, Phil. Diss. Leuven

Itkonen/Joki/Peltola 1975: E. Itkonen / A.J. Joki /R. Peltola, Suomen kielen etymologinen sanakirja, V, Helsinki (Lexico Societatis Fenno-Ugricae 12, 5)

Jensen 1952: H. Jensen, Die indo-europäischen Zahlwörter 10, 100, 1000, Zeitschrift für Phonetik und allgemeine Sprachwissenschaft 6, 50-57

Kawczyński 1888: M. Kawczyński, Germanisch-slavische Etymologien, Archiv für slavische Philologie 11, 607-613

Kent 1929: R.C. Kent, The Labial Nasal before Stops in Primitive Indo-European, in: Donum natalicium Schrijnen, Nijmegen/Utrecht, 342-346

Kiparsky 1934: V. Kiparsky, Die gemeinslavischen Lehnwörter aus dem Germanischen, Helsinki (Annales Academiae Scientiarum Fennicae, B 32, 2)

Klingenschmitt 1982: G. Klingenschmitt, Das altarmenische Verbum, Wiesbaden

Kluge 1901: F. Kluge, Vorgeschichte der altgermanischen Dialekte, in: H. Paul (Hg.), Grundriß der germanischen Philologie, I, ${ }^{2}$ Straßburg, 320-496

- - 1913: Urgermanisch. Vorgeschichte der altgermanischen Dialekte, ${ }^{3}$ Straßburg (Grundriß der germanischen Philologie 2)

Koch 1990: Ch. Koch, Das morphologische System des altkirchenslavischen Verbums, I: Text, München (Münchner Universitäts-Schriften. Reihe der Philosophischen Fakultät 22/I)

Kurschat 1876: F. Kurschat, Grammatik der littauischen Sprache, Halle

Lasch 1914: A. Lasch, Mittelniederdeutsche Grammatik, Halle a. S. (Sammlung kurzer Grammatiken germanischer Dialekte 9)

Lehmann 1986: W.P. Lehmann, A Gothic Etymological Dictionary, Leiden

Leskien 1990: A. Leskien, Handbuch der altbulgarischen (altkirchenslavischen) Sprache. Grammatik, Texte, Glossar, ${ }^{10}$ Heidelberg

Leumann 1942: M. Leumann, Idg. sk im Altindischen und Litauischen, Indogermanische Forschungen 58, 1-26, 113-130

Lexer 1876: M. Lexer, Mittelhochdeutsches Handwörterbuch, II, Leipzig [1974]

Lloyd/Springer 1988: A.L. Lloyd / O. Springer, Etymologisches Wörterbuch des Althochdeutschen, I: - $a$ - bezzisto, Göttingen/Zürich 
Lühr 1977: R. Lühr, Die Dekaden '70-120' im Germanischen, Münchener Studien zur Sprachwissenschaft 36, 59-71

- 1982: Studien zur Sprache des Hildebrandliedes, II: Kommentar, Frankfurt am Main/Bern (Regensburger Beiträge zur deutschen Sprach- und Literaturwissenschaft B/22)

Mayrhofer 1992: M. Mayrhofer, Etymologisches Wörterbuch des Altindoarischen, I, Heidelberg

Meid 1967: W. Meid, Germanische Sprachwissenschaft, III: Wortbildungslehre, Berlin (Sammlung Göschen 1218/ 1218a/1218b)

Meillet 1895: A. Meillet, Étymologies, Indogermanische Forschungen 5, 328-334

Osthoff/Brugmann 1890: H. Osthoff / K. Brugmann, Morphologische Untersuchungen auf dem Gebiete der indogermanischen Sprachen, V, Leipzig

Pedersen 1905: H. Pedersen, Die nasalpräsentia und der slavische akzent, Zeitschrift für vergleichende Sprachforschung 38, 297-421

Peeters 1978: Ch. Peeters, Indo-European *kmtóm oder *kntóm? A Comparative Dilemma, Zeitschrift für vergleichende Sprachforschung 92, 27-28

Pijnenburg 1989: W.J.J. Pijnenburg, Eine germanisch-baltoslawische Isoglosse, Historische Sprachforschung 102, 99-106

Pinault 1989: G.-J. Pinault, Introduction au tokharien, LALIES. Actes des sessions de linguistique et de littérature 7, 5-224

Pokorny 1959: J. Pokorny, Indogermanisches etymologisches Wörterbuch, I, Bern/München

Polomé 1972: E.C. Polomé, Germanic and the other Indo-European Languages, in: F. van Coetsem / H.L. Kufner (Ed.), Toward a Grammar of Proto-Germanic, Tübingen, 43-69

Porzig 1954: W. Porzig, Die Gliederung des indogermanischen Sprachgebiets, Heidelberg

Rix 1976: H. Rix, Historische Grammatik des Griechischen. Laut- und Formenlehre, Darmstadt ( $\left.{ }^{2} 1992\right)$

- 1991: Urindogermanisch $* \hat{g}^{h}$ eslo- in den südindogermanischen Ausdrücken für "1000", in: L. Isebaert (Ed.), Studia etymologica indoeuropaea. Memoriae A.J. van Windekens (1915-1989) dicata, Leuven (Orientalia Lovaniensia analecta 45), 225-231

Rosenkranz 1955: B. Rosenkranz, Historische Laut- und Formenlehre des Altbulgarischen (Altkirchenslavischen), Heidelberg

Ross/Berns 1992: A.S.C. Ross/J. Berns, Germanic, in Gvozdanović 1992: 555-715

Sadnik/Aitzetmüller 1955: L. Sadnik/R. Aitzetmüller, Handwörterbuch zu den altkirchenslavischen Texten, Heidelberg/'s-Gravenhage

Schade 1872/1882: O. Schade, Altdeutsches Wörterbuch, II, Halle a. S. [1965] 
Schelesniker 1987: H. Schelesniker, Die Schichten des urslavischen Wortschatzes, in: W. Meid (Hg.), Studien zum indogermanischen Wortschatz, Innsbruck (Innsbrucker Beiträge zur Sprachwissenschaft 52), 227-244

Schmalstieg 1971: W. Schmalstieg, Die Entwicklung der ā-Deklination im Slavischen, Zeitschrift für slavische Philologie 36, 130-146

Senn 1966: A. Senn, Handbuch der litauischen Sprache, I: Grammatik, Heidelberg

Senn/Salys 1963: A. Senn/A. Salys, Wörterbuch der litauischen Schriftsprache. Litauisch-Deutsch, IV, Heidelberg

Shevelov 1964: G.Y. Shevelov, A prehistory of Slavic. The historical phonology of Common Slavic, Heidelberg

Sievers/Brunner 1965: K. Brunner, Altenglische Grammatik nach der angelsächsischen Grammatik von E.Sievers, ${ }^{3}$ Tübingen (Sammlung kurzer Grammatiken germanischer Dialekte A3)

Sobolevskij 1912: A. Sobolevskij, Besprechung von: C. Mladenov, [Alte germ. Elemente in slav. Sprachen] (bulg.), Sofia 1910, Archiv für slavische Philologie 33, $473-482$

Stang 1942: Chr.S. Stang, Das slavische und baltische Verbum, Oslo (Skrifter utg. av Det Norske Videnskaps-Akademi i Oslo, II. Hist.-Filos. Klasse, 1942 No. 1)

- - 1966: Vergleichende Grammatik der Baltischen Sprachen, Oslo/Bergen/Troms $\varnothing$

- - 1972: Lexikalische Sonderübereinstimmungen zwischen dem Slavischen, Baltischen und Germanischen, Oslo/Bergen/Troms $\varnothing$ (Skrifter utg. av Det Norske Videnskaps-Akademi i Oslo II. Hist.-Filos. Klasse, Ny Serie 11)

Stocki 1950: R.S. Stocki, Slavs and Teutons. The Oldest Germanic-Slavic Relations, Milwaukee, Wisconsin

Szemerényi 1960: O. Szemerényi, Studies in the Indo-European system of numerals, Heidelberg

— 1970. 1990: Einführung in die vergleichende Sprachwissenschaft, ${ }^{1.4}$ Darmstadt

Uhlenbeck 1906: C.C. Uhlenbeck, Aanteekeningen bij Gotische etymologieën, Tijdschrift voor nederlandsche taal en letterkunde 25, 245-306

Vaillant 1948: A. Vaillant, Notules, Revue des études slaves 24, 176-184

- - 1958: Grammaire comparée des langues slaves, II: Morphologie, 2: Flexion pronominale, Lyon/Paris

Vasmer 1950. 1958: M. Vasmer, Russisches etymologisches Wörterbuch, I. II, Heidelberg

Vondrák 1924: W. Vondrák, Vergleichende Slavische Grammatik, I: Lautlehre und Stammbildungslehre, ${ }^{2}$ Göttingen

Wackernagel 1957: J. Wackernagel, Altindische Grammatik, II,1: Einleitung zur Wortlehre. Nominalkomposition, ${ }^{2}$ Göttingen 
Walde/Pokorny 1930: A. Walde/J. Pokorny, Vergleichendes Wörterbuch der indogermanischen Sprachen, I, Berlin/Leipzig

Windekens 1941: A.J. van Windekens, Lexique étymologique des dialectes tokhariens, Louvain (Bibliothèque du Muséon 11)

- - 1976. 1979: Le Tokharien confronté avec les autres langues indo-européennes, I: La phonétique et le vocabulaire. II,1: La morphologie nominale, Louvain (Travaux... de l'Université catholique néerlandaise de Louvain 11.12)

Winter 1969: W. Winter, Analogischer Sprachwandel und semantische Struktur, Folia Linguistica 3, 29-45

_ - 1992: Tocharian, in: Gvozdanović 1992: 97-161

\author{
Povzetek \\ K SEMANTIFIKACII ŠTEVNIKOV: LEKSEM “TISOČ” - GERMANSKO-BALTOSLOVANSKA \\ IZOGLOSA?
}

V indœevropskih jezikih so števniki, ki označujejo števila večja od "deset", v nasprotju s števniki, ki označujejo manjša števila, jasne tvorbe. Tako stanje je posledica indoevropskega decimalnega števnega sistema. Števnik za "enajst" je tvorjen na podlagi števnika za "deset", števnik za "sto" na podlagi števnika za "deset" ("deset krat deset"), števnik za "tisoč" na podlagi števnika za "sto" ("deset krat sto"). Vpliv takega besedotvornega vzorca je možno zaslediti tudi pri germanskem in baltoslovanskem števniku za "tisoč".

Najnovejša Pijnenburgova razlaga iz zloženke *tūt-sngt-ī ne prepričuje, ker korenski samostalnik *tūtnikjer ni izpričan in ker germansko-baltoslovanski besedotvorni vzorec zloženke iz korenskega samostalnika in deležnika glagola s pomenom "biti" ni dokazljiv. Starejše poskuse razlag germansko-baltoslovanskega števnika za "tisoč" je možno razdeliti v štiri skupine:

1) leksem je zloženka iz ievr. *tūs- "močan, krepek, mnog" in ievr. * $k$ 'mot-ian, *k'mot-iñom, kar je izvedeno iz ievr. k' motóm "sto";

2) leksem je izpeljanka z (deležniško) pripono *-ent- *-ont, *-ngt- iz ievr. *tūs-; semkaj je potrebno prišteti tudi Hampovo (1973: 174) rekonstrukcijo *tū-sk'-ont-, deležnik sedanjika na *-sk'-;

3) leksem je izposojenka, ali germanska iz slovanščine ali pa slovanska iz germanščine;

4) leksem za "tisoč" je bil v baltščini, slovanščini in germanščini neodvisno v vsaki jezikovni skupini posebej zložen iz *tüs- in leksema za "sto".

Razlaga pod 1) ni verjetna zaradi prevoja v csl. ( $Q:$ ę) in stšved. (búsand : púsund) kot tudi a) zaradi nedokazijivega prehoda ievr. *-sk'- v balt. $-s t$-, b) ker bi se ievr. *túHs-k'mot-ih 2 razvilo v csl. *tyštęšsti in c) ker bi se ievr. *túHs-k'mot-ih2 z medglasnim *-s-k'- praviloma razvilo v germ. *-sk-. Upoštevajoč možnost, da bi se *-k'mot- v pragerm. *túHs-k'mt-ih2 naslonilo na leksem za "sto" *k'motóm in bi se *-k'mot- v pragerm. *túHs$k$ 'mot-ih2 naslonilo na leksem za "sto" * $k$ 'motóm in bi fonetični razvoj * $k$ ' sledil pravilu obravnave na vzglasju, pa bi pričakovali pragerm. refleks * $p \bar{u} s-\chi u n d \bar{i}$. Takšno pragerm. iztočnico bi lahko potrjevalo stisl. púshund in stisl., runskošved. püshundrað, vendar sta obliki zaradi drugih germ. refleksov, ki medglasnega $-h$ - nimajo, verjetno nastali po ljudskoetimološki naslonitvi na leksem za "sto".

Razlaga pod 2) ni verjetna, ker bi se * $s$ za $u$-jevskim glasom morda razvil $\mathrm{v}$ balt. $\breve{s}$, vsekakor pa v csl. $\chi$ pred temnim samoglasnikom in $\mathrm{v} \check{s}$ pred palatalnim samoglasnikom.

Razlagi pod 3) nista možni, ker bi bilo pragerm. *būsundī kot tudi pragerm. *büsandī v csl. prevzeto $z$ *Q, pragerm. * $d$ pa bi bil v slov. prevzet kot $d$, zato bi pričakovali csl. *tysqždi (lit. *tüsundil*tüšundi). Tudi nasprotna pot izposoje ni verjetna, ker bi bilo praslov. *tyxot' $i$ s * $x$ - v germ. verjetno prevzeto s pragerm. $*$, praslov. možna izhodna oblika *tyšęt $t i$ bi bila v prevzeta s pragerm. ${ }^{*} s$, vprašanje pa je, ali bi se psl. ${ }^{*} e$ v germ. realiziral kot un. 
Razlaga pod 4) o posameznojezikovnem nastanku leksema za "tisoč" bi bila za csl. tysęšti možna. Ob predpostavki, da je izpad vzglasnega $* h$ - v drugem delu zloženke splošnogermanske starosti, je enako možno sklepati tudi za germ. jezike. Toda v balt. bi se zloženka morala realizirati v *tūšimti-. Tudi domneva polne $o$-prevojne stopnje, torej *tūs- + šamti-, izpričanih lit. túkstantis, let. tūkstoš, tūukstuotis ne pojasnjuje. Za tu predlagano razlago pa je odločilnega pomena stprus. tož. mn. tusimtons, ki gotovo vsebuje leksem za "sto", prim. lit. šiñtas, lot. sìmts.

Ker nobena od dosedanjih razlag za germ. in baltoslov. leksem "tisoč" ne vzdrži kritike, se ponuja teza, da je podlago za germ. in baltoslov. leksem za "tisoč" tvoril posamostaljeni sedanjiški deležnik, ki je bil zaradi povezave pomena "tisoč" s "sto" verjetno preoblikovan od leksema za "sto". Ob takšni domnevi se namrex da najbolj preprosto razložiti vsa razhajanja v germanskih, baltskih in slovanskih jezikih. Glede na fonetične razvoje v vseh treh jezikovnih skupinah se kot najbolj verjetna izhodna deležniška osnova izkaže *tūsont-, *tūsngt-. V germanščini je torej izpričana fonetično regularna oblika. Zaradi izglasnega $-i$ (prim. got. pūsundi, mn. püsundjos, csl. tysešsti, tysošti ) je potrebno izhajati iz posamostaljene oblike za ženski spol na *-ī, ki je v balt. pod

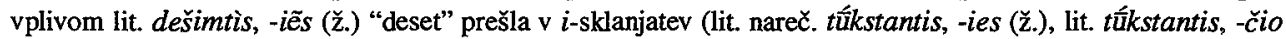
(m.) pod vplivom šim̄tas). Potrditev za koren *tūs- v deležniških oblikah *tūsontī, *tūsntī nudijo germanski jeziki s stisl. pústr (m.) "sovražnost, jeza" v smislu "nadutost, zateklost (od jeze)", nnorv. tūst "šop, šop las, čop",

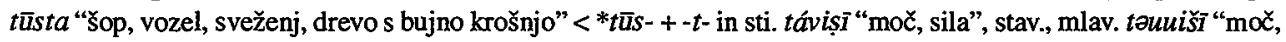
telesna moč" iz korenske oblike *teư⿰氵ss-. Osnovni pomen *tūsontī, *tūsntī je bil "otekajoča (množica); oteklost, kup", prim. pomen "množica" csl. tъma (rus. tъmá) "10 000", kar se ne da ločiti od lit. tùm(s)tas "kup, množica", (Ašmenà) tumstas "1000".

Odstopanja od pričakovanega fonetičnega refleksa se razlagajo:

a) stisl. pushund, stisl. in runskošved. püshundrað imajo - $h$ - pod vplivom leksema za "sto";

b) pričakovana slov. refleksa sta *tyxệt' $i$ in *tyšet' $i$. Pod vplivom pričakovanega slov. refleksa *seto za ide. * ${ }^{*}$ 'móóm se je *tyšet' $i$ preoblikovalo v *tysęt' $i$, ta oblika pa je sprožila zamenjavo $x$ s $s$ tudi v $o$-stopenjski obliki *tyxot' $i$. Ker je bilo pod vplivom Ieksema za "sto" je preoblikovano tudi stprus. tūsimtons, je možno predpostaviti, da je bila ničtostopenjska oblika *tüsngtī pod vplivom leksema za "sto" preoblikovana že v baltoslovanskem obdobju. Ob slov. *tysęt' $i$ z ohranjenim pričakovanim fonetičnim refleksom za leksem "sto" se ponuja možnost razlage nepričakovanega slov. refleksa za leksem "sto" (csl. şto itd.). Tako kot je *tysęt' $i$ nastalo na podlagi oblike *seto "sto", je možno, da je prvotna 0 -stopenjska oblika *tysot' $i$ vplivala na nastanek prevojne variante *soto "sto", ta pa se je v šibki tonični poziciji denazalizirala v *sbto, prim. imensko predpono *sQ-,

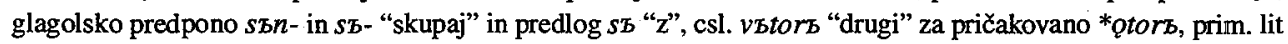
añt(a)ras, sti. ántara-, got. anpar.

c) lit. túukstantis in let. tükstuotis je prav tako možno razložiti z vplivom leksema za "sto". Poleg glavnega števnika *tūsantis je bil tvorjen vrstilni števnik *tūsantas "tisơ̌i" s pridevniškim sklanjatvenim vzorcem. V

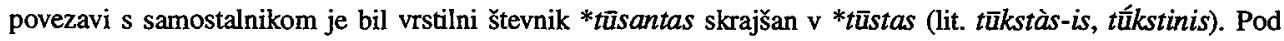
vplivom daljక̌e še ohranjene oblike vrstilnega števnika *tūsantas in drugih vrstilnih števnikov (lit. septiñtas, let. septîtais) pa se je *tūstas podaljšalo v *tūstantas. Pod vplivom vzorca *dešimtis "10" : *dešimtas "10." se je tvoril nov glavni števnik *tūstantis.

Zaradi prikazanih preoblikovanj pod vplivom leksema za "sto" je leksem za "tisoč" lahko imeti za germansko-baltoslovansko izogloso. 